\title{
Uma capitania dos novos tempos: economia, sociedade e política na São Paulo restaurada (1765-1822)
}

\section{Vera Lucia Amaral Ferlini ${ }^{1}$}

RESUMO: $O$ artigo reflete sobre a trajetória da Capitania de São Paulo, a partir de 1750, apontando sua transformação, de fronteira e "boca do sertão", para território estratégico da conquista e defesa das partes meridionais e área economicamente integrada aos circuitos mercantis atlânticos.

PalaVRas-ChaVE: Capitania de São Paulo. Século XVIII. Fronteira. Território. Economia Açucareira.

ABSTRACT: In this article, we reflect upon the history of the Captaincy of São Paulo as from 1750, drawing attention to its transformation from frontier land and "door to the backcountry" into a territory of strategic value for the purposes of conquest and defense of the southern regions, and economically integrated into the Atlantic trade routes.

KEYWORDS: Captaincy of São Paulo. 18 th century. Frontier. Territory. Sugar plantation economy.

O século XVIII representa, na história de Portugal, momento de profundas transformações. A afirmação da dinastia de Bragança encaminhara alianças político-econômicas com a Inglaterra, formalizadas no Tratado de Methuen. A Guerra da Sucessão Espanhola, por sua vez, propiciara aos ingleses, através do Tratado de Utrecht, preponderância nas relações com os espaços coloniais da América, por vantagens estratégicas, comerciais e pelo trato de escravos.

ouro das Gerais, a revestir de luxo o reinado de D. João V, não escondia, porém, a inquietação de membros da elite portuguesa, os "estrangeirados", quanto à armadilha a que o reino se encaminhava. A ilustração e suas luzes, na reflexão dos acadêmicos, apresentava avaliações e soluções para retirar Portugal dessa situação de atraso. A inquietude - não só com a
1. Professora Titular do Departamento de História da Faculdade de Filosofia, Letras e Ciências Humanas da USP e Presidente da Comissão Gestora da Cátedra Jaime Cortesão, da FFLCH/USP. E-mail: <veferlin@usp.br >. 
2. Ver Luís da Cunha (1976).

3. Cf. Fernando Novais (1979, p. 218); e Ana Cristina Araújo ( 2000; 2003).

4. Veja-se discussão detalhada em Lucas Jannoni Soares (2005). O abade Raynal, por exemplo, em sua obra História filosófica e política dos estabelecimentos e do comércio dos europeus nas duas Índias, não se contenta em simplesmente analisar a colônia portuguesa na América e observa de modo crítico como os regimes exclusivos e de monopólio impediam o livre florescimento da colônia.

5. No reino de Portugal, a relação entre o poder político e os eruditos não foi criada pelas Luzes; esse movimento de ideias fez, antes, desaparecer uma situação já dada. Em Portugal, a formação de academias dedicadas ao estudo da literatura nacional vinha ocorrendo pelo menos desde o começo do século XVI, sendo elas, de modo geral, capitaneadas pela primeira nobreza do Reino. A Academia dos Generosos (1647) ilustra isso muito bem: instituída na casa do pai do diplomata D. Luís da Cunha, o guarda-mor da Torre do Tombo António Álvares da Cunha, em seu bojo congregavam-se D. Francisco Manuel de Melo, António de Sousa Macedo, o cosmógrafo Manoel Pimentel, os condes da Ericeira, Rafael Bluteau, o conde de Tarouca (João Gomes da Silva) e o próprio D. Luís da Cunha. E depois, na virada dos Setecentos, muitos destes homens passaram a ser influenciados pelas novas ideias de além-Pirineus, procurando trazer para Portugal os "progressos" dos novos tempos.

6. Cf. Virgílio Noya Pinto (1999). Para uma reavaliação dos índices referentes ao volume de ouro brasileiro chegado à Europa, ver: Michel manutenção de seus domínios, mas também com a população, com a defesa, com a melhoria da produção agrícola e com as manufaturas - está consubstanciada no Testamento Político de D. Luis da Cunha, carta dirigida ao então príncipe D. José, ao final do reinado de seu pai².

Portugal, que nos séculos XV e XVI fora ponta de lança da expansão ultramarina, no século XVIII situava-se em posição excêntrica face aos movimentos de ideias que percorriam de modo corrosivo a civilização do Antigo Regime europeu $^{3}$. Ou seja, os efeitos das Luzes sobre a sociedade portuguesa mostravam, como primeira característica, um modo reflexo e controlado de agir ${ }^{4}$. Em 1751, momento em que se publicavam na França os dois primeiros volumes da Enciclopédie, em Portugal Teodoro de Almeida publicava a Recreação Filosófica (175 1-1 800), com o objetivo de tornar acessível a todas as classes de indivíduos os mais variados e úteis conhecimentos. Portugal, já então, ocupava uma posição periférica, ou melhor, a reboque 5 .

A questão das fronteiras dos domínios ultramarinos portugueses estava em pauta desde o final do século XVII, quando da fundação da Colônia do Sacramento, posto avançado da América portuguesa às margens do Prata. As negociações, desde 1713, encaminharam um longo processo de conhecimento e mapeamento dos domínios, que em 1750 se formalizam no Tratado de Madri.

Esse quadro de preocupação com o avanço econômico, com a afirmação dos domínios, com a atualização de Portugal nos novos rumos do Ocidente, dentro dos parâmetros da llustração, constituiu as diretrizes do reinado de D. José I, o chamado Consulado Pombalino.

Em relação ao Brasil, a partir dessa época a política metropolitana pautou-se pelo incentivo à diversificação agrícola, pela ação de conquista, ocupação e defesa de territórios, e por novas formulações administrativas, fortemente influenciada pelo ideário ilustrado.

Do ponto de vista econômico, no Brasil, o açúcar dividia com o ouro a quase totalidade das exportações, avaliadas em quase 5 milhões de esterlinos. Sofrendo a forte concorrência externa do açúcar holandês caribenho, o açúcar brasileiro também não monopolizava a produção interna da colônia, em que a intensificação das trocas internas apontava diversificação. Por outro lado, o afluxo do ouro brasileiro desde os inícios do século XVIII propiciara a Portugal uma acumulação de capital líquido, capaz de potencializar a industrialização, apesar de uma parcela substantiva dessa riqueza esvair-se para outros países, alimentando igualmente seus processos de industrializaçãob.

As raízes da industrialização portuguesa no período pombalino provêm de um projeto integrado, envolvendo a um só tempo indústria, agricultura e circuito comercial $^{7}$. O estímulo à agricultura tornou-se o esteio da nova políitica econômica, com surpreendentes resultados no Brasil. Produtos para re-exportação pelo Reino (açúcar, cacau, tabaco), alimentos para a população metropolitana (arroz), e matérias-primas para as manufaturas (algodão, couros) enlaçam agricultura e indústria, tornando a caminhada rumo à industrialização uma possibilidade 
concreta. A criação de companhias de comércio privilegiadas fechava o circuito, pois aproximava os espaços coloniais metropolitanos, redesenhando uma nova configuração para o Império Luso-Brasileiro: ações conscientes e objetivas que tornaram Portugal ainda mais dependente do espaço colonial ${ }^{8}$.

$\bigcirc$ papel da capitania de São Paulo nesse período foi fundamental em relação à ocupação meridional e, sem dúvida, o exemplo mais patente da aplicação das novas diretrizes. Ao longo da primeira metade do século XVIII, as terras de São Paulo haviam tomado feição diversa, perdendo territórios e incorporando-se ao espaço administrativo português. Em 1738, a llha de Santa Catarina e o Rio Grande separavam-se do território paulista, unindo-se ao Rio de Janeiro. Em 1740, era Laguna a ser subtraída de sua jurisdição. Em 1748, finalmente, com a criação das capitanias de Goiás e de Mato Grosso, São Paulo perdia sua autonomia política.

Na crescente centralização política da administração real, a extinção da capitania e a perda das áreas mineradoras conferiram a São Paulo novo papel: a unificação da ação bélica do sul, frente às negociações territoriais com a Espanha. A ação militar pressupunha duplo papel, de provisão de víveres e de homens. De certa maneira, a economia crescera, e os paulistas lançavam-se ao comércio de abastecimento: para o Mato Grosso, em monções (frotas fluviais que partiam de Araritaguaba, às margens do Tietêl; e para as Gerais, em tropas de muares.

Nas razões da anexação da capitania ao Rio de Janeiro constavam sua rarefação populacional e sua fragilidade econômica. Mas se a população não vicejava - sangrada para as minas, atirada às lides das tropas e das monções, dispersa nos "sítios volantes" que asseguravam o abastecimento -, o quadro de decadência da capitania não era absoluto, porque nessas correntes de comércio já se semeavam fortunas que, a partir do último quartel do século XVIII, dariam fôlego a São Paulo?.

Mostrara-se inviável a ideia de, na luta contra os castelhanos, ter o sul sob um único mando; e a guerra dos Sete Anos, que colocara Portugal e Espanha novamente em confronto, dera nova dimensão à questão platina, indicando a necessidade de reforço da defesa na Repartição Sul. A distância entre o Rio de Janeiro e o sul, as dificuldades de comunicação, a fragilidade populacional do Rio Grande apontaram a restauração da Capitania de São Paulo, transformada em centro estratégico da posse do sul10.

Não faltaram assim, em 1765, argumentos para a ação da Coroa, devolvendo a São Paulo sua independência administrativa. Ao par de razões gerais do Estado - defesa geopolítica, reativação econômica, incorporação territorial dos domínios da América portuguesa - estavam as solicitações da Câmara de São Paulo e as ponderações do conde da Cunha. Este afirmava ser ela "uma Capitania tão larga e tão distante desta com habitantes excessivamente inquietos e revoltosos, em território abundante em minas de ouro e nas vizinhanças dos Castelhanos, parece que são bastante motivos
Morineau (1986). Sobre o ouro brasileiro na França, ver Christian Morrinson, JeanNoël Barrandon e Cécile Morrison (1999, p. 7-20).

7. A interpretação diverge de diagnósticos clássicos sobre política pombalina, a exemplo da esposada por Jorge Borges Macedo (1982, p. 26). O autor, aí, mantém posições defendidas em trabalhos anteriores, afirmando que a ação política resultaria da crise aurífera e da necessidade de pagar importações. Não deixa de reconhecer, porém, que foram tomadas medidas para concentração e coordenação da produção industrial.

8. Ver José Jobson de Andrade Arruda (2000).

9. Cf. Alice Canabrava (1972)

10. Para um amplo conhecimento de São Paulo no período, consulte-se Heloisa Liberalli Bellotto (1972). 
11. Cf. Conde da Cunha (1895, p. 209-211).

12. Cf. D. Rodrigo de Souza Coutinho (1993, p. 122).

13. Ver Joaquim Romero de Magalhães (1999).

14. Cf. Teotônio José Juzarte (2000, p. 37).

15. Cf. Maria Beatriz Nizza da Silva (1999, p. 154).

16. Ver José Jobson de Andrade Arruda (2000). para deverem ter um bom Governador e Capitão General como eles pretendem e como muitos anos houve"11.

A decisão de instalar um governador em São Paulo, encarregando-o da militarização da capitania (para conter a belicosidade do sul e estender os domínios dos portugueses a oeste) não foi, porém, medida isolada e pontual, face às questões meridionais. Mais do que isso, é demonstração de uma nova política - em relação aos domínios ultramarinos e, em especial, ao Brasil - que, ao final do século, seria sintetizada por D. Rodrigo de Souza Coutinho:

Os domínios de Sua Magestade na Europa não formam senão a capital e o centro de suas vastas possessões. Portugal reduzido a si só, seria dentro de um breve período uma província da Espanha, enquanto servindo de ponto de reunião e de assento à monarquia que se estende ao que possui nas llhas de Europa e África, ao Brasil, às costas orientais e ocidentais da África, e ao que ainda a nossa Real Coroa possui na Ásia, é sem contradição uma das potências que tem dentro de si todos os meios de figurar conspícua e brilhantemente entre as primeiras da Europa ${ }^{12}$.

Era uma capitania dos novos tempos, de um Portugal que buscava reafirmar seu poderio e preeminência. Após dois séculos de vida de fronteira, penetrando em matas e cerrados em busca de pedras e metais preciosos, instalando-se onde melhor se podia viver e defender-se apenas com alguma presença da Coroa, a capitania e sua população deviam ser parte integrante do território e da totalidade da América portuguesa ${ }^{13}$.

O esforço de territorialização da fronteira exigiu sua defesa e o domínio efetivo de novas áreas. Na discutível empreitada da conquista do Iguatemi, o Diário de Navegação do sargento-mor Teotônio José Juzarte mostra, para além da trajetória difícil e heroica, o empenho da nova administração para que se lançasse "em planta todos os rios, todos os países e todas as cousas notáveis que se tiverem descobrido"14. Iniciava-se a época do sertanismo científico, com minuciosos diários, planos e mapas ${ }^{15}$, em diálogo com os conhecimentos das Luzes - usando suas técnicas e inovações, instrumentos e estratégias, mas, ao mesmo tempo, alimentando, com informações, a produção de novos saberes.

Tratava-se, sem dúvida, de um novo paradigma de colonização, e a capitania restaurada afigurava-se campo fértil de realização de propostas apontadas, desde há muito, nas reflexões de ilustrados portugueses, agora tornadas viáveis pela ação decisiva de Sebastião José de Mello, ministro de D. José 16 .

Para isso, deviam ser postos todos os recursos: o levantamento racional e minucioso das populações, a investigação dos recursos naturais, a medição e marcação dos territórios, o estabelecimento de rotas, a elaboração de mapas, o erguimento de fortalezas, a organização e preparo das tropas, a educação da população. Era amplo o arcabouço de conhecimentos e técnicas que precisavam ser ativados. $O$ mundo do conhecimento e o conhecimento do mundo eram partes integrantes da política do período. Sistematicamente apropriado, liberado de suas 
amarras escolásticas, redirecionado e posto a serviço do Estado, o saber avançava além das Academias e integrava o cotidiano da administração ${ }^{17}$.

Durante o período da mineração, a dinâmica comercial da Colônia havia aberto espaço para o crescimento e surgimento de grupos mercantis autônomos que, além do proveito comercial, passaram a investir na produção, reconfigurando a relação de exploração. Essa retomada se deu pelo estabelecimento de companhias de comércio, pela criação de novos espaços, através da defesa e da conquista territorial, fazendo uso de formas racionais, intervencionistas e centralizadoras de administração e governo. Dessa forma, o fomento pombalino buscou reverter para a coroa parte dos lucros da exploração mercantil, mantendo sob seu domínio o espaço colonial.

Na primeira metade do XVIII, graças às descobertas auríferas, a capitania experimentou um crescimento de sua rede mercantil; e o fornecimento de gêneros para o abastecimento interno das minas proporcionou um fomento econômico, estimulando sua economia. Aos poucos, os bandeirantes cederam lugar ao produtor e ao comerciante ${ }^{18}$. Nos trabalhos de Mafalda Zemella, John Monteiro e llana Blaj, é possível observar a revisão de idéias que interpretavam São Paulo como pobre, decadente e isolada ${ }^{19}$. Cada um dos autores, a seu modo e em diferentes níveis, demonstrou como, mesmo não fazendo parte do grande eixo mercantil da colônia, na região paulista, até 1765, desenvolveu-se algum nível de produção, comércio e riqueza.

Contudo, as sucessivas perdas territoriais sofridas pela capitania ao longo de todo o período - além da construção do Caminho Novo, em 1733, ligando as Minas Gerais diretamente ao Rio de Janeiro - formaram um quadro adverso, cujo ápice foi a extinção da capitania em 1748 e sua submissão à jurisdição do Rio ${ }^{20}$. Sem um grande produto de exportação, e perdendo o acesso ao principal mercado de seus produtos de subsistência, a capitania amargou um retrocesso econômico.

Em 1765, a reorganização da capitania surgia como um interesse comum entre a Coroa e a colônia ${ }^{21}$. Portugal, necessitando ampliar, na colônia, a produção de excedentes para equilibrar suas contas, voltava-se para todas possibilidades abertas. Mesmo uma região como São Paulo, marcadamente voltada para a exploração dos sertões, que até então cumprira um papel secundário no processo da colonização portuguesa na América, deveria agora entrar num ritmo mais geral, ou seja, os novos administradores teriam de erigir uma infraestrutura de produção agrícola capaz de gerar excedentes via exportação, portanto, destinada ao comércio internacional e subsumida às suas flutuações.

Maria Thereza Petrone, analisando a lavoura canavieira em São Paulo, aponta dois períodos decisivos: um, é o ano de 1765, e os esforços do Morgado de Mateus em desenvolver a agricultura em nível tal, que chegasse a ser um "empreendimento visando ao mercado mundial"22; o outro, até 1802, é o governo de Antônio Manoel de Mello Castro e Mendonça, indicado como marco da consolidação da lavoura canavieira e da produção de açúcar exportável23.
17. Sobre a política pombalina e a ilustração, ver: Fernando Antonio Novais (1979); Francisco José Calazans Falcon (1982); Iris Kantor (2004); Ana Cristina Araújo (2000; 2003).

18. Cf. Ilana Blaj (2002, p. 285 - 296).

19. Na obra de Blaj citada na nota anterior (p. 39-85), há uma análise fundamental acerca da construção de imagens, na historiografia que trata de São Paulo, desde o século XIX, com o Instituto Histórico e Geográfico de São Paulo, até parte da década de 1990.

20. Cf. Heloísa Liberalli Bellotto (1972, p. 28-33). As perdas são: Minas (1720), Ilha de Santa Catarina e Rio Grande (1738), Laguna (1740), Cuiabá, Goáis e MatoGrosso (1748).

21. Em janeiro de 1765 , o Marquês de Pombal escrevia ao Conde da Cunha, vice-rei do Estado do Brasil, afirmando que "De tudo o referido vem a resultar uma demonstração decisiva de que o dito Plano oferecido pelos Paulistas, não só hé muito útil pelo descobrimento dos haveres, que eles consideram; mas que hoje se faz indispensavelmente necessário; e que nessa certeza se lhe devem fornecer todos os meios possíveis para o prosseguirem". Arquivo do Estado de São Paulo, Avisos-Cartas Régias (1765-1777), C00420.

22. Cf. Maria Thereza Schoper Petrone (1968, p. 12).

23. "A partir de Mello Castro e Mendonça, o açúcar vai adquirindo importância sempre maior, transformando-se num dos fatores do progresso pelo qual a Capitania, depois Província de São Paulo, passou na primeira metade do século XIX." Idem, p. 15. 
24. Idem, p. 25-36

25. Idem, p. 39.

26. Idem, p. 41.

27. Segundo Petrone (1968 p. 7), o "ciclo do açúcar", vai de 1765 até 1850-1851, "quando a exportação de açúcar foi ultrapassada em volume pela do café".

28. Ver José Jobson de Andrade Arruda (2000)
José Jobson Arruda hierarquiza os produtos exportados por Santos e Rio de Janeiro, principais portos escoadouros do açúcar paulista, e aponta o "açúcar branco" como o artigo que teve maior saída, para ambos os portos, durante os anos de 1796 a 1811 :

$$
\begin{gathered}
\text { Exportação de "açúcar branco" 1796-1802 } \\
\text { (em arrobas) }
\end{gathered}
$$

\begin{tabular}{|c|c|c|c|c|}
\hline & Bahia & Pernambuco & Rio de Janeiro & Santos \\
\hline 1796 & 676.163 & 502.538 & 475.672 & 11.817 \\
\hline 1797 & 248.696 & 201.470 & 222.551 & 4.406 \\
\hline 1798 & 434.468 & 342.695 & 801.088 & 82.333 \\
\hline 1799 & 373.188 & 417.114 & 523.868 & - \\
\hline 1800 & 339.718 & 365.296 & 153.035 & - \\
\hline 1801 & 598.985 & 647.753 & 870.282 & - \\
\hline 1802 & 163.662 & 452.857 & 674.481 & - \\
\hline
\end{tabular}

Fonte: José Jobson Arruda (1980, p.360).

Em São Paulo, as áreas produtoras de açúcar localizavam-se no litoral e em duas diferentes áreas da região chamada de "serra acima". Os grandes produtores do litoral eram Ubatuba, São Sebastião e llha Bela, e, mesmo aí, a produção de açúcar sempre teve pouca relevância, sendo ultrapassada pela produção de aguardente ${ }^{24}$. Na região do vale do Paraíba, a primeira das áreas de "serra acima", "que se estende ao longo do caminho para o Rio de Janeiro", os produtores de açúcar eram Guaratinguetá, Lorena, Mogi das Cruzes, São Luiz do Paraitinga, Taubaté e Pindamonhangaba. Maria Thereza Petrone explica o fato de essa região não ter sido grande produtora de açúcar como consequência de aí existirem outros tipos de plantação, ou seja, "a cana de açúcar não monopolizou todas as forças dessa área"25. Já o chamado "quadrilátero do açúcar", a segunda das áreas de "serra acima", e a mais considerável produtora de açúcar da capitania, abrangia o "quadrilátero formado por Sorocaba, Piracicaba, Mogi Guaçu e Jundiai"26, responsável pelo chamado "ciclo do açúcar" 27 .

Do ponto de vista econômico, a instalação da grande lavoura de exportação em São Paulo não reproduziu padrões produtivos e de configuração social que se haviam formado (no Nordeste e no Rio de Janeiro) nos primeiros séculos. Agora, o padrão produtivo, as técnicas, a mentalidade empresarial forjaram-se dentro de uma nova relação, de um novo padrão de colonização, como definido por Jobson Arruda ${ }^{28}$. Os relatos dos governadores, as preocupações das Câmaras, as crônicas de viajantes no período apontam uma nova inserção 
dessa produção, tanto no contexto dos valores de trabalho, como da própria organização das lavouras. Gradativamente, os referenciais econômicos e sociais enquadravam-se, de um lado, em padrões de lucratividade e racionalidade, e, de outro, na crescente valorização do trabalho sistemático. Nesse sentido, tanto as apreciações dos governadores em relação aos pobres-livres da capitania, como a intensa adoção do escravismo nas áreas açucareiras revelam a influência desses referenciais.

As relações entre metrópole e colônia tomam nova feição: as colônias tornam-se mercados consumidores dos produtos industrializados metropolitanos e fornecedoras de matérias-primas e alimentos, nos quadros de uma ampla transformação da economia ocidental, na época da Revolução Industrial. Longe da concepção de uma colônia decadente dos finais do século XVIII, ressurge uma colônia revitalizada no pós-crise aurífera. A internalização dos fluxos de capital dinamizam suas atividades econômicas, descolando-as das conjunturas metropolitanas

A transformação da economia não se deu rapidamente, nem por meio de grandes investimentos iniciais. A participação de capitais privados, inclusive de pequenos roceiros, foi fundamental para o sucesso da empreitada ${ }^{29}$. Em 1772, - Morgado de Mateus escrevia ao Marquês de Pombal:

Para remediar esta falta [de abundantes riquezas], pus em execução as Reais Ordens que V. Ex. ${ }^{a}$ me expediu em dias de julho de 1766 promovendo com toda a eficácia a lavoura dos algodões, e dos trigos, ouro dos arados e a cultura de outros gêneros que a fertilidade destas terras me prometia, procurei a extensão do comércio que se acha livre para S. Majestade convocando os homens de negócio para entrarem nele ${ }^{30}$.

Para alcançar as vantagens a serem auferidas na capitania de São Paulo, os governadores deveriam enfrentar, entre outras dificuldades, a intensa dispersão de sua população, a criação de infraestrutura básica - manter os caminhos em estado de uso, manter as comunicações entre as partes da capitania em funcionamento etc. - além de criar uma administração efetivamente centralizada, capaz de implementar as demandas metropolitanas ao longo de todo o território da capitania ${ }^{31}$. As dificuldades para a realização desses objetivos não seriam poucas, pois os paulistas - "os flagelos dos castelhanos" demonstravam-se avessos a toda intervenção que lhes parecesse tolher sua liberdade de ação. Na questão da dispersão populacional ${ }^{32}$, um dos meios utilizados para fixar a população foi a criação de novas vilas ${ }^{33}$.

$\bigcirc$ período que se inicia em 1765 é um momento emblemático na mudança de rumo que marcou a sociedade do Planalto. Na época, a capitania entrou em novo ritmo, com sua população sofrendo um processo de fixação e com o aumento da parte rentável de sua economia, isto é, de sua parte exportável. $\bigcirc$ açúcar, conhecido na capitania pelo menos desde meados do século XVI quando das primeiras tentativas de implantação em S. Vicente, passou a ser
29. Cf. Maria Luiza Marcílio (2000, p. 82-83). Além disso, na agricultura de subsistência, o papel dos pobres-livres (na figura de pequenos roceiros) é delineado por Stuart Schwarz (2001).

30. Cf. Morgado de Mateus (1946, p. 122 -124).

31. Ver Heloísa Belloto (1972, p. 50).

32. "Entre 1705 (data da criação de Pindamonhangaba) e 1767 (quando ocorrem as fundações levadas a efeito pelo Morgado de Mateus) nenhuma vila foi fundada em território paulista. O reinado de D. João V e o de D. José em seus primeiros tempos estavam voltados exclusivamente para a zona de mineração. Deste modo, para São Paulo não havia necessidade, nem interesse, de expandirlhe a rede a rede urbana já existente no século XVII." Cf. Idem, p. 173. Ver também Sérgio Buarque de Holanda (1966).

33. "A experiência me tem mostrado a grande oposição que têm os Povos às fundações de Povoações Civis: Os pequenos porque querem viver na liberdade de todo o governo e justiça; e os maiores porque querem servir-se daqueles mesmos debaixo do nome de administrados, e têlos como verdadeiros escravos, e daqui nasce o excogitarem os meios possíveis para haver de impedirem o efeito das ditas povoações, porque em toda a parte tenho encontrado os mesmos obstáculos ainda que por diferentes meios." [ortografia atualizada] Morgado de Mateus Oficio enviado ao Conde vicerei, São Paulo, 07 de julho de 1767 , Documentos Interessantes Vol. 23, (1891, p. 205). Administrados eram índios aldeados submetidos ao controle e à proteção da Coroa, o que não impedia a sua utilização como serviçais. 
34. Ver Vera Lucia Amaral Ferlini e Raquel Glezer (2006, p. 14-24); e Maria Thereza Schorer Petrone (1968, p. 12 e ss.). Estudo detalhado da capitania de São Paulo, a partir de 1750 , encontra-se em Luna e Klein (2005).

35. Ver Elizabeth Darwiche Rabelo de Almeida (1972, p. 136).

\section{Idem, p. 148}

37. Ver Heloísa Liberalli Bellotto (1968, p. 257).

38. Ver Florestan Fernandes (1978).

39. Fernando Novais (1997, p. 15) assinala: "No plano econômico, por exemplo, defrontamo-nos com uma produção dominantemente mercantil que imprime a dinâmica ao conjunto) e portanto não mais a economia 'natural' dominante no feudalismo; mas ainda não capitalista, pois a força do traba1ho ainda não se mercantilizara". Sobre a discussão da economia colonial como capitalista, principalmente tomando por base os trabalhos nos engenhos, vejase: Antonio de Barros de Castro (1976; 1984); Maria Sylvia de Carvalho Franco (1984); e Edgar de Decca (1982). Uma excelente e crítica síntese da questão encontra-se em Sedi Hirano (1988). produzido em escala cada vez maior, atingindo posição central na economia paulista no final do XVIIII4.

Os novos rumos administrativos e econômicos tiveram forte influência na organização social da capitania. Ao longo da primeira metade do século, a base mercantil de abastecimento das minas fortalecera uma nova elite de comerciantes, que agora os governantes buscavam integrar aos padrões produtivos de administração. A necessidade de abastecimento das tropas, e a própria constituição de seus efetivos, forçava a integração da população pobre livre. E a introdução dos escravos africanos sinalizava a consolidação de novas distinções sociais.

Elizabeth Darwiche Almeida destaca três elementos de distinção social na São Paulo da segunda metade do século XVIII: terra, genealogia e função social ${ }^{35}$. Indica, ainda, a relação de parentesco na composição de cargos administrativos na capitania: há um caso interessante, de 1796, em que, para eleição de sargento-mor de certa vila, além de dois sujeitos da lista tríplice enviada ao governador serem irmãos, o capitão-mor da vila era pai deles ${ }^{36}$. Heloísa Bellotto, referindo-se aos camaristas e à dificuldade do Morgado de Mateus em lidar com eles, atentou para o período em que a capitania ficou sem governador próprio (1748-1765) como potencializador dessas forças locais. Mais ainda, para a autora, nesse período, formou-se uma estrutura local de redes de poder dos vereadores da capitania "em grupos, cujos membros ligados entre si, dispunham do governo das vilas, segundo seus caprichos e interesses" ${ }^{\prime \prime 7}$.

O monopólio fundiário da exploração escravista, no período colonial, forjou poderosa articulação social, base de sólida estrutura de mando, e encaminhou, a partir do final do século XVIII, o processo de emancipação, a internalização da acumulação, e a afirmação do Estado nacional. Longo processo, em que a terra, apropriada através de privilégio real, explorada pelo braço escravo, constituiu-se na pedra angular da dominação.

A compreensão dessa forma contraditória e híbrida de organização social passa, necessariamente, pelo entendimento da expansão portuguesa, em suas dimensões econômicas, territoriais e políticas. Na colônia, o processo colonial reproduziu (também produzindo uma nova realidade) formas de dominação vigentes na metrópole, associando a afirmação/expansão do poder político imperial aos interesses dos grupos mercantis e às aspirações daqueles que, ao engajarem-se nas lides das conquistas, buscaram, nas novas terras, posições e honrarias ${ }^{38}$.

Várias têm sido as explicações para a maneira específica como se organizaram a sociedade e o poder político português dos descobrimentos. Sem dúvida, o caráter mercantil da empreitada - aquilo que, na longa duração, deu sentido ao movimento - mascarou tanto as outras motivações que impulsionaram as navegações, como tendeu a homogeneizar, sob a aparência de racionalidade e estatismo, os aspectos contraditórios, nivelando, sob a capa do capitalismo em formação, as formas não capitalistas ${ }^{39}$.

Em sua afirmação, a dominação portuguesa exigiv a concentração do 
poder nas mãos dos agentes da colonização, para exercer as funções necessárias ao cumprimento do próprio papel da Colônia. E, mesmo se não levarmos em conta a necessidade de produção em larga escala para o mercado mundial lque nas condições do grande capital mercantil requeria grandes unidades produtivas), a existência de espaços vazios na colônia condicionava à disponibilidade de terras, a priori, a disposição de trabalhar para os outros e, dessa forma, dificultava o estabelecimento, no espaço americano, de organização social e de poder semelhante à vigente em Portugal, onde uma minoria privilegiada, distinta da massa pelo monopólio territorial, dominava uma larga massa despossuída. Dessa forma, na Colônia, a organização fundiária correspondeu, ao mesmo tempo, à constituição de formas de domínio compatíveis às metropolitanas e à concentração de terras; e, além de atender às necessidades mercantis, criou as bases da estrutura de poder. Ao mesmo tempo, significava concentração econômica e configurava a poderosa concentração social, capaz de reproduzir a dominação, definindo, como eixos articuladores da sociedade, não apenas a escravidão, mas a grande propriedade escravista ${ }^{40}$. Se a política de concentração de terras fazia da grande propriedade a base da concentração do poder e da reprodução da dominação metropolitana, o caráter mercantil da produção exigia uma larga base de mão-de-obra destituída, somente possível, nas condições do Brasil, pela compulsoriedade do trabalho ${ }^{41}$.

A grande exploração monocultora e escravista açucareira impediu o desenvolvimento de uma camada de pequenos e médios proprietários, e estes, quando existiam, dependiam do grande proprietário para processar o açúcar ou comprar sua produção de subsistência ${ }^{42}$. Os que não tinham recursos, nem arrendar terras podiam e tornavam-se agregados, vivendo na grande propriedade e prestando serviço para os senhores ${ }^{43}$. Eram elementos essenciais para a manutenção da dominação política, social e, também, para o domínio militar. A preocupação em constituir formas de controle explícito remontam ao Regimento de Tomé de Souza, que enfatiza a obrigação da defesa por parte dos senhores e o armazenamento de armas (que devem dar para 10 ou 20 indivíduos), o que pressupunha certo número de homens a serviço do senhor ${ }^{44}$. Isto foi reforçado com a criação dos corpos de ordenança (1575), e de Auxiliares (meados do XVII). Seus comandantes, os capitães-generais só poderiam ser escolhidos entre os homens-bons, e a eles cabia o recrutamento dos corpos miliciais, daí a importância de sua clientela, a consolidar ainda mais a dominação dos grandes proprietários ${ }^{45}$. Na prática, estruturavam núcleos fortes de poder local - formado pelos proprietários, mais seus familiares, seus agregados, seus escravos - que resistiram até $\mathrm{O}$ século XIX ${ }^{46}$.

A partir do final do século XVIII, as transformações político econômicas que levaram à Independência, obscureceram o processo de impedimento e exclusão do acesso à terra de largas camadas que, desde o período colonial, arranjavam-se - articuladas ou não à grande produção de exportação - em regime de pequena exploração, como posseiros, arrendatários, agregados etc. Uma vasta população sertaneja, de quem, com maior frequência, os cronistas e
40. "No caso, a relação patrimonial permitia condicionar a transferência da ordem estamental que servia existente em Portugal: as concessões de sesmarias demarcavam as estruturas de poder que não podiam nem deviam ser destruídas, como condição histórica para manter a estratificação estamental que servia de base social à existência $\mathrm{e}$ ao fortalecimento do Estado patrimonial". Cf. Florestan Fernandes (1978, p. 34). Sobre o patrimonialismo na monarquia portuguesa, ver Eduardo d'Oliveira França (1946); e, ainda, Raymundo Faoro (1975).

41. Um fértil debate sobre a gênese do escravismo moderno travou-se, no Brasil, nas décadas de 1960 e 1970 , polarizando-se entre a explicação da fronteira aberta e a criação de um "proletário" possível para o capital, nas condições coloniais. Para uma síntese, veja-se Vera Lucia Amaral Ferlini (1988, p. 17-24).

42. Ver Laima Mesgravis (1983, p. 805).

43. Ver Eni de Mesquita Samara (1977).

44. Cf. Tomé de Souza (1983).

45. Ver Nanci Leonzo (1954).

46. Minucioso estudo sobre a questão está em Patrícia Ann Aufderheide (1976) 
47. Ver Cecília Helena L. de Salles Oliveira (1999); especialmente o capítulo Usurpação e violência: a definição do espaço dos cidadãos.

48. Uma interessante abordagem da desqualificação desses homens e suas roças está em Dora Shellard Correia (1997).

49. Ver Louis Couty (1881).

50. Os dados levantados por Tarcísio Botelho (1998) apontam significativa população livre no século XIX.

51. Cf. Douglas Libby (1988, p. 361)

52. Cf. E. P. Thompson (1991).

53. No final do século XVIII, a relação entre os paulistas e o trabalho (na acepção acima descrita) não era, aos olhos dos governadores, muito boa. O Morgado de Mateus não se conformava com o fato de terem aqueles homens uma vida nômade e dispersa. Trabalhavam o necessário para o seu sustento e iam descansar, jogar, pescar, caçar... sem produzir um excedente que permitisse o florescimento do comércio. Ver Maria Odila Leite da Silva Dias (1984, p. 16).

54. Ver Stuart Schwartz (2001, p. 128-129). viajantes do período nos falam. Na época da Independência, essa população - expressiva, mas incômoda - constituiu "massa de manobra" das elites dominantes em luta pela hegemonia política, mas, ao mesmo tempo, fundamentou temores de insurreição e pôs em risco o processo desenfreado de apropriação de terras ${ }^{47}$. Enquanto crescia a necessidade de braços para a lavoura de exportação, cerceada pela inexorável desarticulação internacional do tráfico, essas populações - arraigadas ao uso tradicional da terra, e refratárias e insubmissas à disciplinarização plantacionista - vão sendo desqualificadas econômica, social e politicamente ${ }^{48}$. E, ao lado do processo de modernização que encaminhou as modificações do Império, vai se construindo o mito da exiguidade e incapacidade de nossa população livre, a ponto de Couty observar que o Brasil não tinha povo ${ }^{49}$.

Mas tal população existia, era expressiva, como hoje mostram os estudos sobre a demografia do período; mas, mais do que isso, estava enraizada, integrada à grande exploração (ou à margem dela) ${ }^{50}$. A polarização da sociedade colonial em duas categorias fundamentais - senhores e escravos - mascarada por valores estamentais, escondia extensa gama de grupos intermediários que compunham o universo social: mercadores, roceiros artesãos, oficiais de açúcar, lavradores de roça e mesmo desocupados ${ }^{51}$.

Desde o alvorecer da ldade Moderna, os pobres-livres foram um tema de preocupação das elites metropolitanas, assim como o foram, depois, das coloniais. O termo-chave "vadio" percorreu o período e indicava a mudança na percepção medieval de pobreza. Com a ascensão gradativa do trabalho (na acepção capitalista) e do próprio capitalismo, o pobre deixou de ser digno de caridade e passou a ser alvo de uma legislação que buscava levá-lo ao trabalho, à geração de riqueza para outros ${ }^{52}$. Na colônia existia, contudo, um elemento complicador dessa passagem: a escravidão. O sistema escravista revelava a olhos nus a crueza da exploração capitalista do trabalho ${ }^{53}$. Logo, na colônia, o não-trabalho apareceria como uma forma de nobilitação ou de simples resistência à dominação metropolitana.

As transformações profundas que marcaram o fim do Antigo Sistema Colonial não se restringiram, pois, ao âmbito do exclusivo. Em São Paulo, o estímulo redefiniu a grande produção escravista, exigindo um padrão de atividades sistematizadas e organizadas, adequado aos princípios produtivos em voga, considerando atrasada a pequena produção em roças, tanto de algodão como de mandioca, produto da indolência dos pobres-livres.

No caso particular da colônia portuguesa na América, a crise foi experimentada como um processo de estreitamento de relações com a metrópole - em crescendo, desde o chamado "Renascimento Agrícola", até o fim do pacto colonial, em 1808. ${ }^{54} \bigcirc$ setor exportador estreitava relações com a Metrópole, para onde se dirigiam os seus produtos e de onde provinha a sua legitimidade enquanto camada dominante. Desse modo, a Coroa ganhou relevo como o elemento complementar dessa dinâmica, realizando esforços para manter e ampliar os espaços de suas mercadorias nos quadros do comércio europeu. 
Em São Paulo, os novos rumos sinalizavam aumento da cisão fundamental entre os interesses da maioria da população (escravos, índios, lavradores excluídos do comércio externo etc.) e os da atividade econômica ${ }^{55}$ : crises de abastecimento, a cana preferida, em detrimento do feijão, do arroz, do milho, da mandioca ${ }^{56}$. Nesse quadro, a passagem de São Paulo de centro periférico de exploração do sertão para uma unidade integrada diretamente ao mercado exportador seria o desafio imposto aos governadores e à população da capitania.

\section{REFERÊNCIAS}

\section{FONTES}

Avisos-Cartas Régias (1765-1777) - C00420, Arquivo do Estado de São Paulo, São Paulo.

MATEUS, Morgado de [Luís António de Sousa Botelho Mourão]. Oficio enviado ao Conde vice-rei, São Paulo, 7 de julho de 1767. In: ARQUIVO DO ESTADO DE SÃO PAULO. Documentos interessantes para a bistória e costumes de São Paulo, v. 23. São Paulo: Tipografia Aurora; Arquivo do Estado, 1891. p. 205.

MATEUS, Morgado de [Luís António de Sousa Botelho Mourão]. Carta, "Para o mesmo senhor", 26 de fevereiro de 1772. In: ARQUIVO DO ESTADO DE SÃO PAULO. Documentos interessantes para a história e costumes de São Paulo, v. 69. São Paulo: Tipografia Aurora; Arquivo do Estado, 1946. p. 122-124.

\section{LIVROS, ARTIGOS E TESES}

ALMEIDA, Elizabeth Darwiche Rabelo de. As elites na sociedade paulista na segunda metade do século XVIII. Tese (Doutorado em História) - Faculdade de Filosofia, Letras e Ciências Humanas, Universidade de São Paulo, São Paulo, 1972.

ARAÚJO, Ana Cristina (Org.). O marques de Pombal e a Universidade. Coimbra: Imprensa da Universidade, 2000.

A cultura das luzes em Portugal: temas e problemas. Lisboa: Horizonte, 2003.

ARRUDA, José Jobson de Andrade. Decadência ou crise do Império Luso-Brasileiro: o novo padrão de colonização do século XVII. Revista da USP, São Paulo, n. 50, p. 66-79, 2000.

AUFDERHEIDE, Patrícia Ann. Order and Violence: Social Deviance and Social Control in Brazil, 1780-1840. 1976. Tese (Doutorado em História) - University of Minnesota, Minnesota, 1976 (mimeo).

BELLOTTO, Heloisa Liberalli. Autoridade e conflito no Brasil colonial: O governo do Morgado de Mateus em São Paulo. São Paulo: Conselho Estadual de Artes e Ciências Humanas, 1972.

BLAJ, Ilana. A trama das tensões: o processo de mercantilização de São Paulo colonial (1681-1721). São Paulo: Humanitas; Fapesp, 2002.
55. Ver Caio Prado Junior (1994, p. 19 e ss.).

56. "Numa organização como essa [a colônia], os dois elementos que fundamentalmente compõem o ciclo econômico - produção e consumo, ou seja, organização produtiva e mercado consumidor - se acham desarticulados entre si e não se integram um com o outro e por isso não se completam e mutuamente se amparam e estimulam." Cf. Caio Prado Junior (1994, p. 351). 
BOTElHO, Tarcísio. População e Nação no Brasil do Século XIX. 1998. Tese (Doutorado em História Social) - Faculdade de Filosofia, Letras e Ciências Humanas, Universidade de São Paulo, São Paulo, 1998.

CANABRAVA, Alice. Uma economia de decadência: os níveis de riqueza na Capitania de São Paulo. 1765-1777. Revista Brasileira de Economia, Rio de Janeiro, v. 26, n. 4, p. 95-123, out.-dez. 1972 .

CASTRO, Antonio de Barros de. Escravos e senbores de engenbos do Brasil: um estudo sobre os trabalhos do açúcar e a política econômica dos senhores. 1976. Tese (Doutorado em Economia) Unicamp, São Paulo.

As mãos e os pés do senhor de engenho. In: PINHEIRO, Paulo Sérgio. Trabalbo escravo, economia e sociedade. Rio de Janeiro: Paz e Terra, 1984.

CORREIA, Dora Shellard. Paisagens sobrepostas. 1997. Tese (Doutorado em História Econômica) - Faculdade de Filosofia, Letras e Ciências Humanas, Universidade de São Paulo, São Paulo, 1997.

COUTINHO, Rodrigo de Souza. Memória sobre o melboramento dos domínios de sua Majestade na América. Textos políticos, económicos e financeiros (1783-1811). Lisboa: Banco de Portugal, 1993.

COUTY, Louis. L'Esclavage au Brésil. Paris, Guilaumin, 1881.

CUNHA, Conde da. In: ARQUIVO DO ESTADO DE SÃO PAULO. Documentos interessantes para a bistória e costumes de São Paulo, v. 11. São Paulo: Tipografia Aurora; Arquivo do Estado, 1895 .

CUNHA, Luis da. Testamento político [c.1746]. São Paulo: Alfa-Ômega, 1976.

DECCA, Edgar de. O nascimento das fábricas. São Paulo, Brasiliense, 1982.

DIAS, Maria Odila Leite da Silva. Quotidiano e poder em São Paulo no século XIX. São Paulo: Brasiliense, 1984 .

FALCON, Francisco José Calazans. A época pombalina. São Paulo: Ática, 1982.

FAORO, Raymundo. Os Donos do Poder. 2. ed. Porto Alegre: Globo; São Paulo: Edusp, 1975. $2 \mathrm{v}$.

FERLINI, Vera Lucia Amaral. Terra, trabalbo e poder. O mundo dos engenhos no Nordeste colonial. São Paulo: Brasiliense, 1988.

; GLEZER, Raquel. O açúcar em São Paulo XVI ao XIX. SEMINÁRIO DE HISTORIA DO AÇÚCAR: HISTÓRIA E CULTURA MATERIAL, 1. Atas... São Paulo: FFLCH/USP, p. 14-24, 2006.

FERNANDES, Florestan. Circuito fechado. São Paulo: Hucitec, 1978.

FRANÇA, Eduardo d'Oliveira. O poder real em Portugal e as origens do Absolutismo. 1946. Tese (Doutorado em História) - Faculdade de Filosofia, Ciências e Letras, Universidade de São Paulo, São Paulo, 1946. 
FRANCO, Maria Sylvia de Carvalho. Organização social do trabalho no Período Colonial. In: PINHEIRO, Paulo Sérgio. Trabalbo escravo, economia e sociedade. Rio de Janeiro: Paz e Terra, 1984.

HIRANO, Sedi. Pré-capitalismo e capitalismo. São Paulo: Hucitec, 1988.

HOLANDA, Sérgio Buarque de. Movimentos populacionais no século XVII. Revista do Instituto de Estudos Brasileiros, São Paulo, v. 1, n. 1, p. 55-111, 1966.

JUZARTE, Teotônio José. Diário da navegação. Org. Jonas Soares de Souza; Miyoko Makino. São Paulo: Edusp; Imprensa Oficial do Estado, 2000.

KANTOR, Íris. Esquecidos e renascidos. São Paulo: Hucitec, 2004.

LEONZO, Nanci. As Companbias de Ordenança na Capitania de São Paulo. 1975. Dissertação (Mestrado em História) - Faculdade de Filosofia, Letras e Ciências Humanas, Universidade de São Paulo, São Paulo, 1975.

LIBBY, Douglas. Transformação e trabalbo em uma economia escravista. São Paulo: Brasiliense, 1988.

LUNA, Francisco Vidal; KLEIN, Herbert S. Evolução da sociedade e economia escravista de São Paulo, de 1750 a 1850. São Paulo : Edusp, 2006

MACEDO, Jorge Borges. O marquês de Pombal, 1699-1782. Lisboa: Biblioteca Nacional, 1982.

MAGALHÃES, Joaquim Romero de. Apresentação. Oceanos, Lisboa, n. 40, p. 5, out.-dez. 1999.

MARCÍlIO, Maria Luiza Crescimento demográfico e evolução agrária paulista. São Paulo: Hucitec; Edusp, 2000.

MESGRAVIS, Laima Os aspectos estamentais da estrutura social do Brasil Colônia. Estudos Econômicos (IPE/USP), São Paulo, v. 13, p. 799-811, 1983.

MORINEAU, Michel. Incroyables gazettes et fabuleux métaux. Le retour des trésor américains d'aprés les gazettes holandaises (XVIe et XVIIIe siècles). Cambridge: Cambridge University Press; Paris: Éditions Maisons des Sciences de l'Homme, 1986.

MORRINSON, Christian et al. Or du Brésil, monnaie et croissance en France au XVIIIe siècle. Paris: CNRS Éditions, 1999. p. 7-20.

NOVAIS, Fernando. Portugal e Brasil na Crise do Antigo Sistema Colonial. São Paulo: Hucitec, 1979,p. 218

História da Vida Privada: condições de privacidade na colônia, 1. São Paulo: Cia. das Letras, 1997.

OLIVEIRA, Cecília Helena L. de Salles. A astúcia liberal. São Paulo: Icone; USF, 1999.

PETRONE, Maria Thereza Schorer. A lavoura canavieira em São Paulo: expansão e declínio (1765-1851). São Paulo: Difusão Européia do Livro, 1968.

PINTO, Virgílio Noya. O ouro brasileiro e o comércio anglo-português. São Paulo: Nacional, 1999. 
PRADO JUNIOR, Caio. Formação do Brasil contemporâneo. 23. ed. São Paulo: Brasiliense, 1994.

A revolução brasileira. São Paulo: Brasiliense, 1996.

SAMARA, Eni de Mesquita. O papel do agregado na região de Itu, de 1780 a 1830. São Paulo: Museu Paulista, 1977.

SCHWARZ, Stuart. Roceiros e escravidão: alimentando o Brasil nos fins do período colonial. In: Escravos, Roceiros e Rebeldes. Trad. Jussara Simões. Bauru: Edusc, 2001.

SILVA, Maria Beatriz Nizza da. A saga dos sertanistas. Oceanos, Lisboa, n. 40, p. 154, out.-dez. 1999.

SOARES, Lucas Jannoni. Presença dos bomens livres pobres na sociedade colonial da América portuguesa. São Paulo (1765-1775). 2005. Dissertação (Mestrado em História Econômica) Faculdade de Filosofia, Letras e Ciências Humanas, Universidade de São Paulo, São Paulo, 2005.

SOUZA, Tomé. Regimento de Tomé de Souza. In: INSTITUTO DO AÇÚCAR E DO ÁLCOOL. Documentos para a História do Açúcar (Legislação). Rio de Janeiro: IAA, 1954.

THOMPSON, E. P. O tempo, a disciplina do trabalho e o capitalismo industrial. In: SILVA, T. T. da (Org.). Trabalbo, educação e prática social: por uma teoria da formação bumana. Porto Alegre: Artes Médicas, 1991. p. 44-93.

Artigo apresentado em 8/2008. Aprovado em 3/2009. 